\title{
Factor Analysis of Meteo-parameters on the Stage of Growth of Birch Leaves
}

\author{
PM Mazurkin ${ }^{1 *}$ and AI Kudryashova ${ }^{2}$ \\ ${ }^{1}$ Doctor of technical Sciences, Volga State University of Technology, Russia \\ ${ }^{2}$ Senior lecturer, Volga State University of Technology, Russia
}

*Corresponding author: PM Mazurkin, Doctor of technical Sciences, Volga State University of Technology, Lenin st., 3, Yoshkar-Ola, 424000, Russia.

Received Date: September 18, 2019

Published Date: September 24, 2019

\begin{abstract}
Of the many meteorological parameters of the site http://rp5.ru weather station identified 27 quantitative factors from 01/05/2018 (bud break) to 20/08/2018 (the moment of maximum growth at the best registered birch leaves). The coefficient of correlation variation, that is, the measure of the functional relationship between weather parameters is 0.2754 . As the influencing variable in the first place «Dew point temperature», in the second - «Maximum gust of wind». The same parameters were leading in the rating indicators. Only six strong patterns turned out between nine meteorological parameters with a correlation coefficient of at least 0.7 . Two more formulas with an average adequacy between air temperature and dew point temperature. Of greatest significance are the maximum gust of wind and wind speed at 0.9339 and 0.9321 . The coefficient of correlative variation increased instead of 0.2754 for trends to 0.3135 with wavelet dynamics. The azimuth in the dynamics does not move at all, which indicates the independence of the geographical factor, measured by points, from the meteorological parameters. The remaining parameters of wind and wind gusts require a reduction in measurement error. When modeling with trends and wavelets, relative humidity was the first among influencing variables, and dew point temperature was second. In third place was the pressure tendency of atmospheric pressure. Among the indicators in the first place remained the temperature of the dew point, the second - the relative humidity of the air, the third - the maximum gust of wind. For the growth stage of birch leaves, the most important meteorological parameters are air humidity and dew point temperature.
\end{abstract}

Keywords: Growth stage of birch leaves; Meteorological parameters; Three-hour measurements; Dynamics; Regularities; Ratings of factors

\section{Introduction}

In different parts of the Earth at weather stations accumulated a lot of time series, for example, on various parameters of air in the surface layer. One of the conditions for further development of meteorology is the identification of stable regularities [1-9] on the basis of accumulated statistical data at meteorological stations. And these patterns allow you to better understand the past and predict certain possible behaviors of people making decisions. At the same time, our method of identification of the General wavelet equation (solitary wave) from the measured statistical data will allow to Supplement and clarify the climate mitigation scenarios up to 2100 , described in article [1]. Another condition will be the identification of the scenarios of human behavior by their quantitative data of the dynamics of each factor taken into account by their reliability. In this case, only those scenarios for which the wave equations of high adequacy will be obtained will be reliable.
The water regime of meadows [3,4] and carbon dynamics in Europe [5] change according to wavelets of universal design [2].

Then we distinguish two types of quanta of behavior: first, in dynamics, each factor is divided into the sum of wavelets, that is, in time, the factor is represented as a bundle of solitary waves (solitons) and this process is characterized as quantum certainty; secondly, the mutual influence of the factors taken into account with uniform or uneven periodicity of measurements additionally obtains quantum entanglement or uncertainty in some measurement intervals.

Thus, any phenomenon or process can be estimated by the level of adequacy (correlation coefficient) of decomposition of the functional connectivity of the system into quantum certainty and quantum entanglement. It turned out that in quantum meteorology 
$[6,8]$ can distinguish the quantum fitometeorology [7,9] for vegetation period of plants. We have identified another quantum of plant behavior - this is the stage of growth from budding to reaching the maximum size of the leaves on the example of birch. Thus, the quanta of time in climatology and meteorology are now as follows: cycles of solar activity, year (the cycle of the Earth's revolution around the Sun), month due to the influence of the moon on life, day (the cycle of the Earth's revolution around itself), threehour or hour periods of measurements that allow to determine the daily cycles, as well as five-minute measurements that give the most reliable dynamics of meteorological parameters. To this we add new quanta of time: the period of vegetation of plants on phenological studies, the stage of growth in the growing season.

Plantgrowth is a complexprocess, itis based on such fundamental phenomena as rhythm, polarity, differentiation, irritability, correlation. These processes are common for ontogenesis of living organisms. Ontogenesis - individual development of the body from zygote (or vegetative germ) to natural death. Thanks to the active activity of meristems and photosynthetic activity of leaves, the green plant acquires a number of features that characterize its growth. In the process of plant ontogenesis growth is observed during the main stages of its life cycle [10-12]. Therefore, in further studies it is possible to identify patterns of influence of meteorological parameters on the dynamics of vegetative organs of plants, and these patterns to assess the geoecological state of the area. This method we called as indirect biotesting of the quality of the environment surrounding birch

\section{Materials and Methods}

\section{Source data}

Of the many meteorological parameters on the site http:// rp5.ru for Yoshkar-Ola, we identified nine quantitative factors: $t$ - air temperature at a height of 2 meters above the ground, ${ }^{\circ} \mathrm{C}$; $P$ - atmospheric pressure at station level, millimeters of mercury; $\mathrm{Pa}$ - baric tendency of atmospheric pressure for the last 3 hours, millimeters of mercury; $U$ - relative humidity at a height of 2 meters above the ground, \%; $\boldsymbol{D}$ - wind direction (azimuth) at an altitude of 10-12 meters above the ground, degrees; ff- wind speed at an altitude of 10-12 meters above the ground, m/s; ff10- the maximum value of the wind gust at an altitude of 10-12 meters above the ground, $\mathrm{m} / \mathrm{s}$; $f f$ - the minimum value of the wind gust at an altitude of 10-12 meters above the ground, m/s; $T d-$ dew point temperature at a height of 2 meters above the ground, ${ }^{\circ} \mathrm{C}$.

Table 1: Data from Yoshkar-Ola weather station http://rp5.ru (Russia, WMO_ID=27485, sampling 01/05/2018 for 20/08/2018, all days and hours).

\begin{tabular}{|c|c|c|c|c|c|c|c|c|c|c|c|}
\hline $\begin{array}{l}\text { № } \\
\mathbf{p} / \mathbf{p}\end{array}$ & Date and hours & Time $\tau$, day & $t$ & $P$ & $P a$ & $\boldsymbol{U}$ & $D D$ & $F f$ & $f f 10$ & $f f 3$ & Td \\
\hline 1 & 01.05.2018 00:00 & 0.000 & 5.5 & 747.6 & 0.5 & 94 & 315 & 1 & 3 & 3 & 4.6 \\
\hline 2 & 01.05.2018 03:00 & 0.125 & 5.0 & 749.0 & 1.4 & 94 & 0 & 3 & 4 & 4 & 4.1 \\
\hline 3 & 01.05.2018 06:00 & 0.250 & 5.2 & 751.0 & 2.0 & 91 & 0 & 2 & 3 & 5 & 3.8 \\
\hline 4 & 01.05.2018 09:00 & 0.375 & 8.2 & 752.2 & 1.2 & 78 & 45 & 3 & 5 & 5 & 4.6 \\
\hline 5 & 01.05.2018 12:00 & 0.500 & 10.8 & 753.1 & 0.9 & 56 & 135 & 2 & 4 & 6 & 2.4 \\
\hline 6 & 01.05.2018 15:00 & 0.625 & 12.7 & 753.7 & 0.6 & 50 & 247.5 & 1 & 3 & 4 & 2.4 \\
\hline 7 & 01.05.2018 18:00 & 0.750 & 13.2 & 753.7 & 0.0 & 46 & 180 & 2 & 4 & 5 & 1.6 \\
\hline 8 & 01.05.2018 21:00 & 0.875 & 9.8 & 753.5 & -0.2 & 63 & 180 & 2 & 3 & 4 & 3.1 \\
\hline 9 & 02.05.2018 00:00 & 1.000 & 8.4 & 753.2 & -0.3 & 78 & 180 & 2 & 3 & 6 & 4.8 \\
\hline 10 & 02.05.2018 03:00 & 1.125 & 7.4 & 752.8 & -0.4 & 87 & 135 & 4 & 6 & 6 & 5.4 \\
\hline$\ldots$ & $\ldots$ & $\ldots$ & $\ldots$ & $\ldots$ & $\ldots$ & $\ldots$ & $\ldots$ & $\ldots$ & $\ldots$ & $\ldots$ & $\ldots$ \\
\hline 890 & $20.08 .201803: 00$ & 111.125 & 13.4 & 752.3 & -1.1 & 87 & 180 & 2 & 3 & 3 & 11.3 \\
\hline 891 & $20.08 .201806: 00$ & 111.250 & 12.6 & 751.6 & -0.7 & 88 & 180 & 2 & 3 & 3 & 10.7 \\
\hline 892 & $20.08 .201809: 00$ & 111.375 & 16.0 & 750.6 & -1.0 & 76 & 180 & 3 & 4 & 5 & 11.8 \\
\hline 893 & $20.08 .201812: 00$ & 111.500 & 15.6 & 749.9 & -0.7 & 87 & 180 & 3 & - & - & 13.5 \\
\hline 894 & 20.08 .2018 15:00 & 111.625 & 21.0 & 749.2 & -0.7 & 71 & 202.5 & 3 & 5 & 6 & 15.5 \\
\hline 895 & 20.08 .2018 18:00 & 111.750 & 20.5 & 748.6 & -0.6 & 80 & 180 & 2 & 3 & 5 & 16.9 \\
\hline 896 & $20.08 .201821: 00$ & 111.875 & 17.7 & 748.4 & -0.2 & 86 & 225 & 3 & 4 & 5 & 15.3 \\
\hline
\end{tabular}

Weather station Yoshkar-Ola, Russia, WMO_ID $=27485$, the sample was taken from 01/05/2018 (Bud break) to 20/08/2018 (the time of maximum growth in the best birch leaves hanging). Then sharply deviating points were excluded from the data array. Designation of meteorological parameters is given in http://rp5. ru/archive.php?wmo_id=27485\&lang=ru. The power of statistical sampling in nine meteorological parameters amounted to 896 lines (Table 1).
In factor analysis, time acts as a system-forming factor providing binary relations between nine weather parameters. Therefore, the adequacy of the dynamics models is taken into account in the diagonal cells of the correlation matrix. In the article, the dynamics is given mainly by trends, and all additional wave equations detected before the measurement error in the form of a bundle of wavelets are given in other articles. 


\section{Results}

\section{Factor analysis identification of the trend}

The trend is formed when the period of oscillation tends to infinity. A linear model is always used at the beginning of the identification process. All models of dynamics (trend at the beginning of the identification process, then a set of oscillations) and binary relations (in such relations there are no fluctuations of meteorological parameters) are identified by a two-term trend formula

$$
y=\operatorname{aexp}\left(-b x^{c}\right)+d x^{e} \exp \left(-f x^{g}\right),(1)
$$

where - the dependent measure, - influencing variable, - model parameters (1) identified from a simple linear model to a complex pattern in the software environment CurveExpert-1.40 (http:// www.curveexpert.net/). The first term is a modified us by the law of Laplace (in math), Mandelbrot (in physics), texts-pearl (biology) and Pareto (econometrics). Modification is the intensity of growth or decline $c \neq 1$. And the second component is a biotechnical law [2]. Table 2 shows the correlation matrix of binary relations and the rating of nine factors obtained by the identification method [2] according to table 1 . In our example, in the diagonal cells we put the correlation coefficient of the trend on the dynamics models from 01/05/2018 to 20/08/2018 (Table 2).

Table 2: Correlation matrix of factor analysis and rating of factors after identification of the trend pattern (1).

\begin{tabular}{|c|c|c|c|c|c|c|c|c|c|c|c|}
\hline \multirow{2}{*}{$\begin{array}{c}\text { Influencing } \\
\text { factors(characteristic } x \text { ) }\end{array}$} & \multicolumn{9}{|c|}{ Dependent factors (indicators $y$ ) } & \multirow{2}{*}{$\underset{\Sigma r}{\operatorname{Amount}}$} & \multirow{2}{*}{$\underset{I_{x}}{\text { Place }}$} \\
\hline & $t$ & $P$ & $P a$ & $\boldsymbol{U}$ & $D D$ & $F f$ & ff10 & ff3 & Td & & \\
\hline$t,{ }^{\circ} \mathrm{C}$ & 0.5746 & 0.1727 & 0.3531 & 0.4579 & 0.0630 & 0.0342 & 0.0137 & 0.0201 & 0.6994 & 2.3887 & 6 \\
\hline$P$, mm of mercury & 0.0754 & 0.4552 & 0.0665 & 0.2664 & 0.2332 & 0.1005 & 0.1323 & 0.1737 & 0.2883 & 1.7915 & 8 \\
\hline$P a, m m$ of mercury & 0.4283 & 0.1237 & 0 & 0.2955 & 0.0999 & 0.2774 & 0.2996 & 0.3176 & 0.2664 & 2.1084 & 7 \\
\hline$U, \%$ & 0.4061 & 0.2694 & 0.3059 & 0.3414 & 0.0003 & 0.2851 & 0.3423 & 0.3336 & 0.4320 & 2.7161 & 5 \\
\hline$D D$, degrees & 0.2387 & 0.3672 & 0.3399 & 0.0011 & 0.0784 & 0.1743 & 0.1375 & 0.1701 & 0.2750 & 1.7822 & 9 \\
\hline$F f, \mathrm{~m} / \mathrm{s}$ & 0.1126 & 0.1191 & 0.0189 & 0.3072 & 0.0216 & 0.2345 & 0.9339 & 0.7524 & 0.2698 & 2.7700 & 3 \\
\hline$f f 10, \mathrm{~m} / \mathrm{s}$ & 0.0137 & 0.1503 & 0.0473 & 0.3603 & 0.0092 & 0.9321 & 0.2594 & 0.7971 & 0.2608 & 2.8302 & 2 \\
\hline$f f 3, \mathrm{~m} / \mathrm{s}$ & 0.0201 & 0.1964 & 0.0142 & 0.3764 & 0.0136 & 0.7564 & 0.7985 & 0.2940 & 0.2921 & 2.7617 & 4 \\
\hline $\mathrm{Td},{ }^{\circ} \mathrm{C}$ & 0.6783 & 0.3162 & 0.1004 & 0.4199 & 0.0538 & 0.2598 & 0.2561 & 0.2834 & 0.7892 & 3.1571 & 1 \\
\hline Amount $\Sigma r$ & 2.5478 & 2.1702 & 1.2462 & 2.8261 & 0.5730 & 3.0543 & 3.1733 & 3.1420 & 3.5730 & 22.3059 & \\
\hline Place $I_{y}$ & 6 & 7 & 8 & 5 & 9 & 4 & 2 & 3 & 1 & - & 0.2754 \\
\hline
\end{tabular}

The coefficient of correlation of variations is the measure of functional relationship between the parameters of the system (the weather at the weather station) is equal to $22.3059 / 9^{2}=$ 0.2754. As the influencing variable on the first place there was a meteorological parameter «dew point Temperature», on the second - «the Maximum wind gust». The same parameters were leading in the ranking of indicators. And other factors were not the best places in the ratings of influencing variables and indicators. Thus, the generally accepted concept of the greatest impact of air temperature in fitometeorology turned out to be false: in the growth stage of the leaves of the silver birch, the air temperature was only in sixth place.

Table 3: Correlation matrix medium and strong binary relations with a correlation coefficient of at least 0.5 .

\begin{tabular}{|c|c|c|c|c|c|}
\hline \multirow{2}{*}{$\begin{array}{c}\text { Influencing factors } \\
(\text { characteristic } \boldsymbol{x} \text { ) }\end{array}$} & \multicolumn{5}{|c|}{ Dependent factors (indicators $y$ ) } \\
\cline { 3 - 6 } & $\boldsymbol{t}$ & $\boldsymbol{F f}$ & $\boldsymbol{f f 1 0}$ & $\boldsymbol{f f 3}$ & $\boldsymbol{T d}$ \\
\hline$t,{ }^{\circ} \mathrm{C}$ & & & & & 0.6994 \\
\hline$F f, \mathrm{~m} / \mathrm{s}$ & & & 0.9339 & 0.7524 & \\
\hline$f f 10, \mathrm{~m} / \mathrm{s}$ & & 0.9321 & & 0.7971 & \\
\hline$f f 3, \mathrm{~m} / \mathrm{s}$ & & 0.7564 & 0.7985 & & \\
\hline$T d,{ }^{\circ} \mathrm{C}$ & 0.6783 & & & & \\
\hline
\end{tabular}

In total, there were six strong regularities according to the formula (1) with the mutual connection between the nine meteorological parameters with a correlation coefficient of at least 0.7 (Table 3).

Two more formulas with average adequacy refer to mutual relations between air temperature and dew point temperature. Thus, among the values of meteorological parameters at the stage of growth of birch leaves, the most important are the maximum wind gust and wind speed with correlation coefficients 0.9339 and 0.9321 . A relative humidity and air temperature, directly affecting the dynamics of growth and development of vegetative organs of plants with favorable photosynthesis, are less significant compared to the parameters of the movement of air masses.

Then it can be argued that the movement of air becomes at the stage of plant growth systematically acting cause. At the same time, with increasing speed and gusts of air movement, the vital activity of plants deteriorates, and they are more stressed. Therefore, wind speed, maximum and minimum wind gusts become limiting factors for plants, creating limits of productivity in the process of growth and development. In the dynamics of growth and development of plants to a certain limit, for example, the maximum size of the leaves, the main effect is the dynamics of the sums of dew point temperatures, relative humidity and air temperatures.

\section{Medium and strong binary relationship trends}

Table 4 shows the parameters (1) for the eight models in Table 3 (Table 4). 
Table 4: Parameters model (1) of mean and strong binary relations.

\begin{tabular}{|c|c|c|c|c|c|c|c|c|c|}
\hline \multirow{3}{*}{ Variable $x$} & \multirow{3}{*}{ Indicator $y$} & \multicolumn{7}{|c|}{ Trend $y=a \exp \left(-b x^{c}\right)+d x^{e} \exp \left(-f x^{g}\right)$} & \multirow{3}{*}{ Coeff.corr.r } \\
\hline & & \multicolumn{3}{|c|}{ Exponential law } & \multicolumn{4}{|c|}{ Biotechnical law } & \\
\hline & & $a$ & $b$ & $c$ & $d$ & $e$ & $f$ & $g$ & \\
\hline$F f$ & ff 10 & 1.14991 & 0.00021705 & 6.30897 & 0.89015 & 1.45889 & $6.41001 \mathrm{e}-5$ & 4.07871 & 0.9339 \\
\hline ff10 & $F f$ & 0.30193 & 0 & 0 & 0.49889 & 1 & 0 & 0 & 0.9321 \\
\hline$f f 3$ & ff 10 & 0.97975 & -0.037107 & 1 & 0.28872 & 1.37384 & 0.00072697 & 2.22042 & 0.7985 \\
\hline$f f 10$ & $f f 3$ & 2.34432 & 0.10952 & 1 & 1.10580 & 0.97829 & 0 & 0 & 0.7971 \\
\hline$f f 3$ & $F f$ & 0.92887 & -0.016994 & 1 & 0.059185 & 1.95752 & 0.019135 & 1.47898 & 0.7564 \\
\hline$F f$ & $f f 3$ & 2.79312 & 0.023926 & 2.87778 & 1.28293 & 1.29936 & $1.87415 \mathrm{e}-5$ & 4.56322 & 0.7524 \\
\hline$t$ & $T d$ & -6.73988 & 0.58132 & 1 & 0.062782 & 6.12880 & 3.79134 & 0.41249 & 0.6994 \\
\hline$T d$ & $t$ & $4.85188 \mathrm{e} 6$ & 10.88112 & 0.094352 & 0.0016696 & 3.24711 & 0.016974 & 1.35053 & 0.6783 \\
\hline
\end{tabular}

A mutual relationship between the temperature of adequacy were average. Three factors of air movement in table 3 gave a symmetrical picture and were strong with a correlation coefficient of not less than 0.7 .

Table 4 shows that the design of the models is varied. The simplest model was the linear second model of the influence of maximum wind gusts on the wind speed with a correlation coefficient of 0.9321 . More complex was the model number 4, containing the sum of Laplace's law and the exponential law.
Models 3, 5 and 7, in which the second term is a biotechnical law, became even more complicated in design. And the complete design (1) have models № 1, 6 and 8. Strong level of adequacy of the model the relationship between parameters of air movement is graphically shown in Figure 1. One can see that we need a finer gradation of intervals of values of the measurements. Otherwise it is impossible to decompose these dynamics of these factors into a set of oscillations and there is a structural quantum entanglement [6-9] (Figure 1).

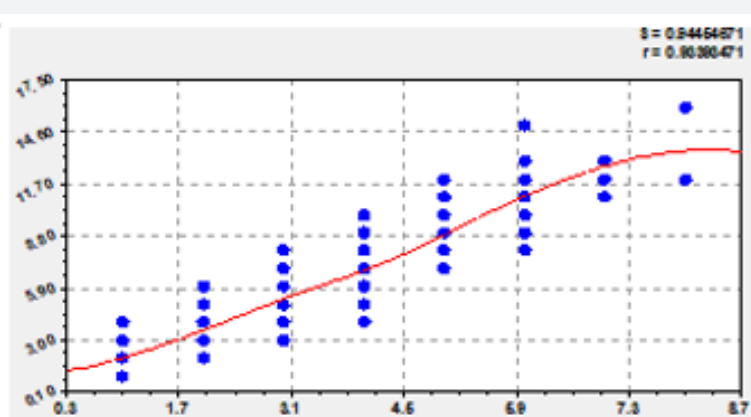

Wind speed at maximum gusts

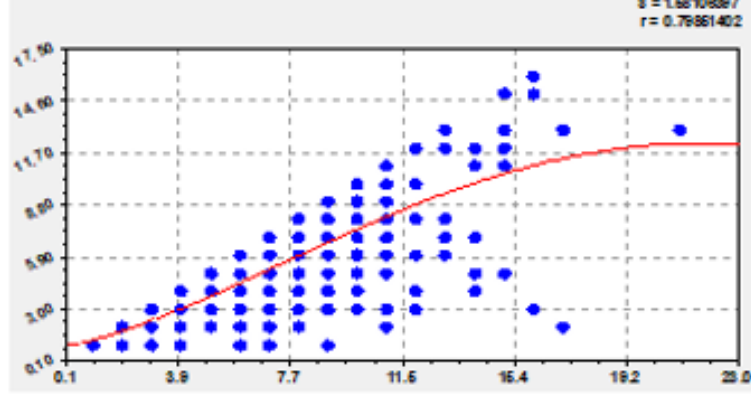

Minimal gusts at the maximum

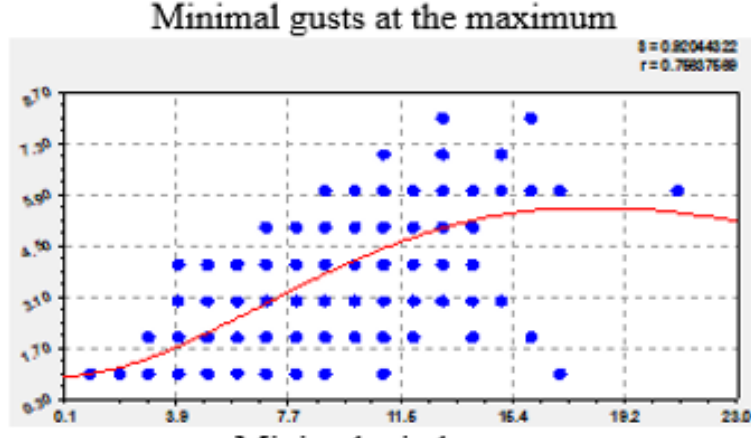

Minimal wind gusts

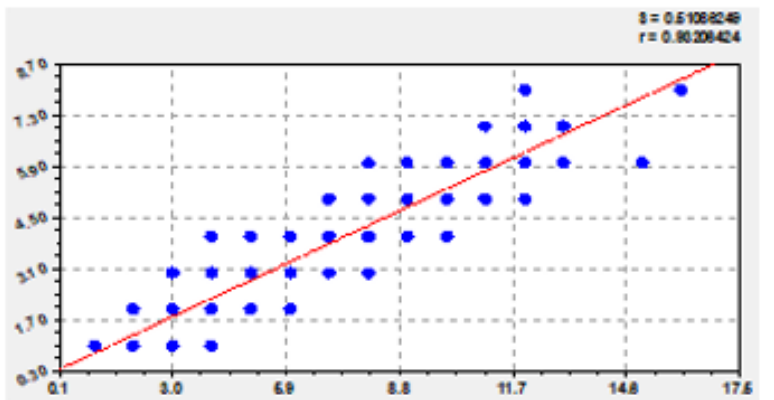

Peak gusts on the wind speed

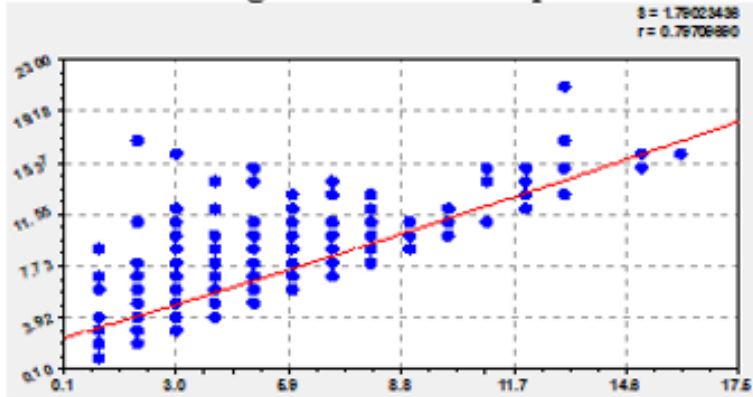

Peak gusts at the minimum

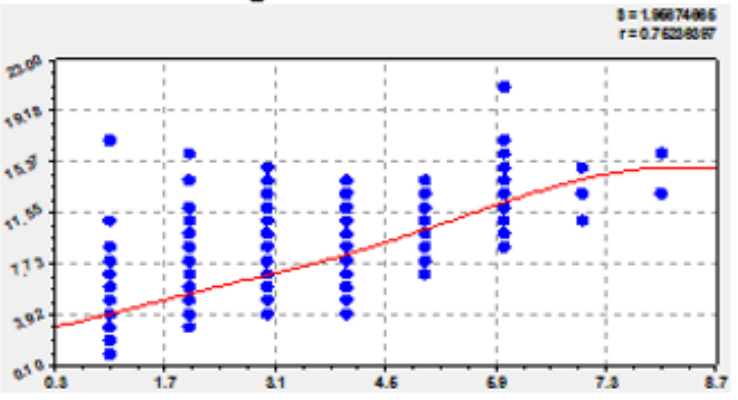

Wind speed gusts at the minimum

Figure 1: Strong binary relationships between meteorological parameters. 
In addition to the wind azimuth and three factors of air movement, the other five factors (temperature, pressure, baric tendency, relative humidity and dew point temperature) have high quantum certainty and are decomposed into dozens of asymmetric wavelets in dynamics. These five factors have a small gradation of measurements. Because of this, the decomposition of the dynamics into individual oscillations occurs up to the measurement error. For example, it is not suitable to measure the azimuth of the Rumba through a gradation of 22.5 degrees. Many meteorological factors have no quantitative measurements. To identify patterns on them, it is necessary to think about the units of measurement. The more accurate the measurements are in three hours, the better the models. Average on adequacy of communication between themselves have air temperature and dew point temperature (Figure 2). Quantum entanglement in binary relations manifests itself clearly from the residuals in figure 2 . They are simply not further modeled and represent a kind of "noise" in the form of chaotically arranged points. The dynamics of the same factors in the measurement time is a bundle of dozens of wavelets. Therefore, the time series gets high quantum certainty (Figure 2).

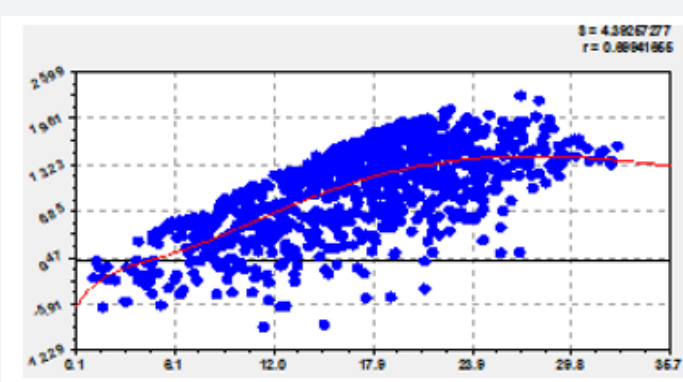

Air temperature dew point

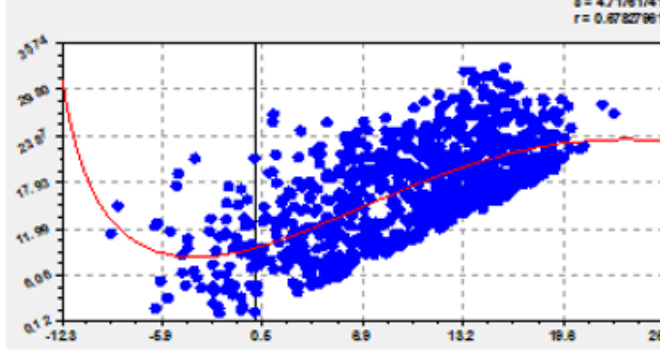

The dew point temperature of the air

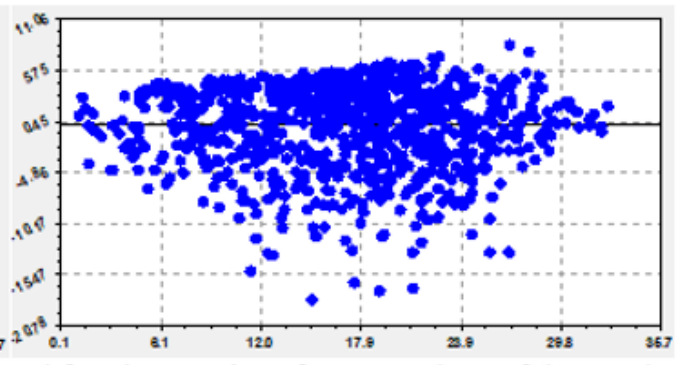

After the remains of two members of the trend

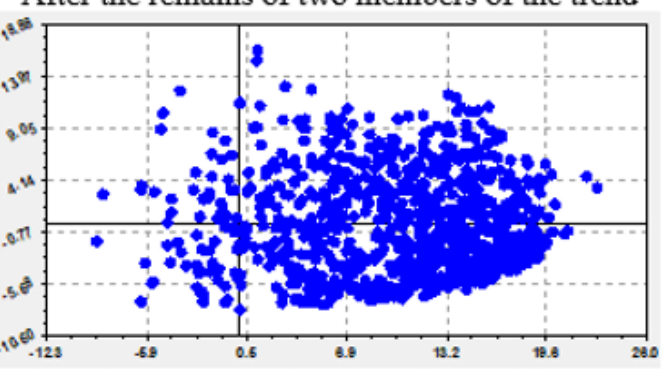

After the remains of two members of the trend

Figure 2: Average of a binary relationship between the temperatures.

Why is it that there are no functional links between individual meteorological factors, except for the trend? We don't know. The stochasticity of climate and weather is very high. But much depends on the dimensions themselves.

\section{Discussion}

\section{Factor analysis identification of the trend and wavelets}

As already mentioned, wavelets appear only in the dynamics of five meteorological parameters. These factors are measured with highly fractional measurement scales. For the rough scale of measurements typical for wind azimuth and three parameters of air movement, only one wavelet was obtained [6-9], which slightly increased the adequacy of the three-membered formula (Table 5). For five factors, which in dynamics can be a complete wavelet analysis to the measurement error, the diagonal cells were put the number 1 . The coefficient of correlation variation of the system of nine factors increased instead of 0.2754 for trend models to $25.3934 / 9^{2}=0.3135$. The azimuth in the dynamics does not shift at all, which indicates the independence of this geographical factor, measured by the Rumba, from the meteorological parameters. Other parameters of wind and wind gusts require further reduction of measurement error (Table 5).

Table 5: Correlation matrix of factor analysis and rating of factors trend (1) and a complete wavelet analysis of the dynamics from 01/05 till 20/08/2018.

\begin{tabular}{|c|c|c|c|c|c|c|c|c|c|c|c|}
\hline \multirow{2}{*}{$\begin{array}{l}\text { Influencing factors } \\
\text { (characteristic } x \text { ) }\end{array}$} & \multicolumn{9}{|c|}{ Dependent factors (indicators $y$ ) } & \multirow{2}{*}{ Amount $\Sigma r$} & \multirow{2}{*}{ Place $I$} \\
\hline & $t$ & $P$ & $P a$ & $U$ & $D D$ & Ff & ff10 & $f f 3$ & $T d$ & & \\
\hline$t,{ }^{0} \mathrm{C}$ & 1 & 0.1727 & 0.3531 & 0.4579 & 0.0630 & 0.0342 & 0.0137 & 0.0201 & 0.6994 & 2.8141 & 7 \\
\hline$P$, mm of mercury & 0.0754 & 1 & 0.0665 & 0.2664 & 0.2332 & 0.1005 & 0.1323 & 0.1737 & 0.2883 & 2.3363 & 8 \\
\hline$P a$, mm of mercury & 0.4283 & 0.1237 & 1 & 0.2955 & 0.0999 & 0.2774 & 0.2996 & 0.3176 & 0.2664 & 3.1084 & 3 \\
\hline$U, \%$ & 0.4061 & 0.2694 & 0.3059 & 1 & 0.0003 & 0.2851 & 0.3423 & 0.3336 & 0.4320 & 3.3747 & 1 \\
\hline$D D$, degrees & 0.2387 & 0.3672 & 0.3399 & 0.0011 & 0.0784 & 0.1743 & 0.1375 & 0.1701 & 0.2750 & 1.7822 & 9 \\
\hline$F f, \mathrm{~m} / \mathrm{s}$ & 0.1126 & 0.1191 & 0.0189 & 0.3072 & 0.0216 & 0.3264 & 0.9339 & 0.7524 & 0.2698 & 2.8619 & 5 \\
\hline$f f 10, \mathrm{~m} / \mathrm{s}$ & 0.0137 & 0.1503 & 0.0473 & 0.3603 & 0.0092 & 0.9321 & 0.3275 & 0.7971 & 0.2608 & 2.8983 & 4 \\
\hline$f f 3, \mathrm{~m} / \mathrm{s}$ & 0.0201 & 0.1964 & 0.0142 & 0.3764 & 0.0136 & 0.7564 & 0.7985 & 0.3819 & 0.2921 & 2.8496 & 6 \\
\hline
\end{tabular}




\begin{tabular}{|c|c|c|c|c|c|c|c|c|c|c|c|}
\hline$T d,{ }^{\circ} \mathrm{C}$ & 0.6783 & 0.3162 & 0.1004 & 0.4199 & 0.0538 & 0.2598 & 0.2561 & 0.2834 & 1 & 3.3679 & 2 \\
\hline Amount $\Sigma r$ & 2.9732 & 2.7150 & 2.2462 & 3.4847 & 0.5730 & 3.1462 & 3.2414 & 3.2299 & 3.7838 & 25.3934 & - \\
\hline Place $I_{y}$ & 6 & 7 & 8 & 2 & 9 & 5 & 3 & 4 & $\mathbf{1}$ & - & 0.3135 \\
\hline
\end{tabular}

Table 6: Limit values of meteorological parameters at zero values of influencing variables.

\begin{tabular}{|c|c|c|c|c|c|c|c|c|c|}
\hline \multirow{2}{*}{$\begin{array}{c}\text { Influencing factors (characteristic } \\
\boldsymbol{X} \text { ) }\end{array}$} & \multicolumn{9}{|c|}{ Dependent factors (indicators $y$ ) } \\
\cline { 2 - 12 } & $\boldsymbol{t}$ & $\boldsymbol{P}$ & $\boldsymbol{P a}$ & $\boldsymbol{U}$ & $\boldsymbol{D D}$ & $\boldsymbol{F f}$ & $\boldsymbol{f f 1 0}$ & $\boldsymbol{f f 3}$ & $\boldsymbol{T} \boldsymbol{d}$ \\
\hline$T=0^{\circ} \mathrm{C}$ & - & 751.7 & 0.07 & 71.6 & 207.4 & 2.9 & 4.9 & 6.9 & 6.74 \\
\hline$P=0 \mathrm{~mm}$ of mercury & 73.94 & - & -7.38 & 738.1 & - & 36.1 & 158.6 & 132.0 & 221.28 \\
\hline$P A=-5 \mathrm{~mm}$ of mercury & 9.54 & 739.8 & - & 39.1 & 262.4 & 5.3 & 10.4 & 10.8 & 0.67 \\
\hline$U=0 \%$ & 6.86 & 762.0 & -1.05 & - & 188.7 & 4.1 & 8.4 & 9.1 & -139.95 \\
\hline$D D=0$ degrees (North) & 14.64 & 753.3 & 0.30 & 65.4 & - & 3.0 & 5.5 & 7.3 & 6.84 \\
\hline$F f=0 \mathrm{~m} / \mathrm{s}$ & 12.81 & 750.0 & -0.03 & 79.5 & 183.8 & - & 1.2 & 2.8 & 11.50 \\
\hline$f f 10=0 \mathrm{~m} / \mathrm{s}$ & 16.96 & 777.5 & 0.06 & 88.1 & 197.2 & 0.30 & - & 2.3 & 11.50 \\
\hline$f f 3=0 \mathrm{M} / \mathrm{S}$ & 17.42 & 751.0 & -0.03 & 107.4 & 201.3 & 0.9 & 1.0 & - & 12.28 \\
\hline$T d=-15^{\circ} \mathrm{C}$ & 77.43 & 742.8 & 0.13 & 14.47 & 198.2 & 6.1 & 8.5 & 8.6 & - \\
\hline
\end{tabular}

The first place among the influencing variables was taken by the relative humidity of the air, and the second - the dew point temperature. In third place was the baric tendency of atmospheric pressure. Among the dependent indicators in the first place remained the dew point temperature, the second - the relative humidity, the third - the maximum gust of wind. Then it turns out that for the stage of growth of birch leaves hanging the most important meteorological parameters are the relative humidity and dew point temperature. Temperature is considered to be the most influential factor in publications. But it is in table 5 on the effect is in seventh place and as an indicator - the sixth. Plant life is more dependent on air humidity and dew point. At zero values of the influencing variables according to the formulas, we obtain the limit theoretical values of the dependent indicators $y=a$ (Table 6).

At a dew point temperature of $-15{ }^{\circ} \mathrm{C}$ in Table 4 , a limit value of temperature 4 was obtained.85188e 6 or 4.85 million degrees Celsius. This fact shows that plant life is also possible at temperatures inside stars? The application of the law of Laplace gives the temperature of the air $77.43{ }^{\circ} \mathrm{C}$. Almost the same temperature in $73.94{ }^{\circ} \mathrm{C}$ gets the atmosphere at zero pressure of air. From the data of table 6 it is seen that the most dangerous is the influence of variables $P=0 \mathrm{~mm}$ of mercury and $U=0 \%$. When the air in the atmosphere tends to zero pressure, the relative humidity can reach $739.1 \%$. At the same time, the wind speed reaches 36.1 $\mathrm{m} / \mathrm{s}$, the maximum wind gusts will be equal to $158.6 \mathrm{~m} / \mathrm{s}$, and the minimum $-132.0 \mathrm{~m} / \mathrm{s}$. the dew point Temperature will reach $221.28^{\circ} \mathrm{C}$, which is more than twice the boiling point of water, so the oceans and seas will boil and evaporate. After evaporation of water from the earth's surface, the relative humidity will be zero, and this will lead to almost cosmic cold at $-139.95^{\circ} \mathrm{sC}$ for the dew point temperature.

\section{Conclusion}

For each ground-based weather station, it is necessary to study the point distributions of meteorological measurements. Pair connections between meteorological parameters allow studying the quanta behavior of climate and weather for different time periods: long-term, annual, plant ontogenesis period, seasonal, monthly, weekly, daily, hour and minute. This article presents another quantum of time - a stage of growth of birch leaves from Bud $(01 / 05 / 2018)$ to reach the maximum size of the best leaves (20/08/2018).

We distinguish two types of quantum behavior: first, in dynamics, each factor is divided into the sum of wavelets, that is, in time, the factor is represented as a bundle of solitary waves (solitons) and this process is characterized as quantum certainty; secondly, the mutual influence of climatic and meteorological factors with uniform or non-uniform frequency of measurements additionally obtains quantum entanglement in some boundaries of the behavior intervals. Of the nine taken into account meteorological parameters due to the rough measurement scales in the dynamics give a quantum entanglement in the structure of the behavior of four factors: wind azimuth on the Rumba; wind speed; maximum and minimum gusts of wind.

In this case, any phenomenon or process can be estimated by the level of adequacy (correlation coefficient) of the decomposition of the functional connectivity of the system behavior into quantum certainty and quantum entanglement.

The concept of vibrational adaptation in nature suggests that between the selected factors in table 1 , there are dependencies in the form of wave equations. However, it turned out that there is no wave connection between these nine factors at the weather station, which indicates the presence of a sufficiently strong quantum entanglement of meteorological data. If the remains after the wavelet analysis are not further modeled, then experts say about some noise. But we believe that noise can only be called residues that are equal to or less than the measurement error. Therefore, part of the noise exceeding the measurement error should be attributed to quantum entanglement. And the share of parameter values determined by the revealed regularities should be attributed to quantum entanglement or certainty. The coefficient of correlation of variations is the measure of functional relationship between the parameters of the system (the weather at the weather station with 
$01 / 05 / 2018$ for $20 / 08 / 2018$ ) equal 0.2754 . As the influencing variable on the first place there was «dew point temperature», on the second - «the maximum wind gust». The same parameters were leading in the ranking of indicators. In total, there were six strong regularities in the mutual relationship between the nine meteorological parameters with a correlation coefficient of at least 0.7. Two more formulas with average adequacy refer to mutual relations between air temperature and dew point temperature. Among the values of meteorological parameters, which are at the stage of growth of birch leaves, the most important are the maximum wind gust and wind speed with correlation coefficients 0.9339 and 0.9321 . The correlative coefficient of variation of the system of the nine factors increased is 0.2754 for model trends to 0.3135 if the dynamics wavelets. The azimuth in the dynamics does not shift at all, which indicates the independence of this geographical factor, measured by the Rumba, from the meteorological parameters. Other parameters of wind and wind gusts require further reduction of measurement error by increasing the fractional measurement scales. When modeling trends and wavelets, the first place among the influencing variables was taken by the relative humidity of the air, and the second - the dew point temperature. In third place was the baric tendency of atmospheric pressure. Among the dependent indicators in the first place remained the dew point temperature, the second - the relative humidity, the third - the maximum gust of wind. For the stage of growth of birch leaves hanging the most important meteorological parameters are the relative humidity and dew point temperature.

\section{References}

1. Millar RJ, Fuglestvedt JS, Friedlingstein P (2017) Emission budgets and pathways consistent with limiting warming to $1.5^{\circ} \mathrm{C}$. Nature Geosci 10 .
2. Mazurkin PM (2014) Method of identification. International Multidisciplinary Scientific Geo Conference, Geology and Mining Ecology Management. SGEM 1(6): 427-434.

3. Mazurkin PM (2018) Influence of Parameters of Water Regime and Hydrological Changes on the Pasture. Biostat Biometrics Open Acc J 6(4): 555695.

4. Mazurkin PM (2018) Wave patterns of annual global carbon dynamics. Materials of the International Conference «Research transfer» Reports (part 2) Beijing, PRC: 164-191.

5. Mazurkin PM, Kudryashova AI (2018) Factor analysis of annual global carbon dynamics. Materials of the International Conference «Research transfer» Reports (part 2). Nov. 28. Beijing, PRC: 192-224.

6. Mazurkin PM, Kudryashova AI (2019) Quantum meteorology: factor analysis of the three-hour measurements of four Meteorological parameters for the years 2012-2018. American Scientific Journal (24): 15-28.

7. Mazurkin PM, Kudryashova AI (2019) Quantum fitopatologia: factor analysis of the three-hour measurements of four meteorological parameters during the vegetation periods 2012-2018 American Scientific Journal (24): 28-43.

8. Mazurkin PM, Kudryashova AI (2019) Quantum meteorology: quanta behavior of meteorological parameters on a three hour measurements betweenthe Decem. solstices Journal of Modern Technology and Engineering 4(1): 20-36.

9. Mazurkin PM, Kudryashova AI (2019) Quanta of behavior of meteorological parameters on three-hour measurements during the growing season of birch American Scientific Journal (24): 59-75.

10. Polgar CA, Primack RB (2011) Leaf-out phenology of temperatewoody plants: from trees toecosystems // New Phytologist 191: 926-941.

11. Rousi M., Pusenius J (2005) Variations in phenology and growth of European white birch (BetulaPendula) clones. Heron PublishingVictoria, Canada. Tree Physiology 25: 201-210.

12. Zhang Y, Bielory L, Georgopoulos P (2014) Climate change effect on Betula(birch) and Quercus(oak) pollenseasons in US. Int J Biometeorol 58(5): 909-919. 